\title{
Perdas fermentativas e estabilidade aeróbia de silagens de cana-de-açúcar tratadas com cal virgem e cloreto de sódio
}

\author{
Adauton Vilela de Rezende ${ }^{1}$, Carlos Henrique Silveira Rabelo ${ }^{2}$, Flávio Henrique Silveira \\ Rabelo $^{2}$, Denismar Alves Nogueira ${ }^{3}$, Danni Cesar Nogueira Achcar de Faria Junior ${ }^{2}$, Larissa \\ de Ávila Barbosa²
}

\footnotetext{
1 Departamento de Zootecnia da Universidade José do Rosário Vellano/UNIFENAS - MG.

2 Universidade José do Rosário Vellano/UNIFENAS - MG.

${ }^{3}$ Departamento de Ciências Exatas da UNIFAL - MG.
}

RESUMO - Esta pesquisa foi realizada com o objetivo de determinar o efeito da inclusão de cal virgem e cloreto de sódio sobre as perdas fermentativas e a estabilidade aeróbia de silagens de cana-de-açúcar. O delineamento experimental utilizado foi o totalmente ao acaso em esquema de parcelas subdivididas com quatro repetições, de modo que os aditivos foram avaliados nas parcelas (silagem sem aditivo; silagens contendo 0,$5 ; 1,0$ e 2,0\% de cloreto de sódio; e silagens contendo 0,5; 1,0 e 1,5\% de cal virgem na matéria natural) e os tempos de exposição ao oxigênio nas subparcelas. Após 75 dias da ensilagem, os silos foram abertos para determinação dos teores de matéria seca (MS) e da perda de MS por efluente e gases e aferição da temperatura e do pH da silagem. A inclusão de cal nas silagens, independentemente da dose utilizada, proporcionou maior teor de MS e menor perda de MS. As menores temperaturas foram observadas nas silagens tratadas com cloreto de sódio. Os aditivos utilizados, sobretudo o cloreto de sódio, foram eficientes em manter a estabilidade aeróbia da silagem de cana.

Palavras-chave: cal virgem, cloreto de sódio, Saccharum officinarum

\section{Fermentation losses and aerobic stability of sugarcane silages treated with whitewash and sodium chlorite}

\begin{abstract}
The objective of this work was to determine the inclusion of whitewash and sodium chloride on the fermentative losses and aerobic stability of sugarcane silages. It was used a completely randomized experimental design in split plot scheme with four replicates, so the additives were evaluated in the plots (silage without additive, silages containing 0.5; 1.0 and $2.0 \%$ of sodium chloride; and silages containing $0.5 ; 1.0$ and $1.5 \%$ of whitewash, on the basis of natural matter) and the time of exposition to oxygen was evaluated in the subplots. After 75 days from ensilage, silos were opened for determination of the contents of dry matter (DM) and the loss of dry matter by effluent and gases and checking of temperature and $\mathrm{pH}$ of the silage. The addition of whitewash into silages, regardless to the dose utilized, provides greater DM content and smaller loss of DM. The lowest temperatures were found in the silages treated with sodium chloride. The additives utilized were efficient in keeping the aerobic stability of sugar cane silage, particularly sodium chloride.
\end{abstract}

Key Words: Saccharum officinarum, sodium chlorite, whitewash

\section{Introdução}

A ensilagem de cana é uma boa alternativa para uso na alimentação de ruminantes, por apresentar melhor qualidade nutritiva na época seca do ano, quando há maior necessidade de alimento volumoso, além de favorecer a uniformização da rebrota, racionalização da mão-de-obra, padronização de adubações e uso de herbicidas (Cavali et al., 2006). Entretanto, a silagem apresenta alguns entraves em sua produção, como a queda do valor nutritivo após a abertura dos silos (deterioração aeróbia), fenômeno decorrente da penetração de ar no silo. A presença de oxigênio na face do silo e seu respectivo avanço para as camadas internas durante sua utilização determinam a multiplicação de alguns grupos de microrganismos aeróbios que consomem os compostos energéticos presentes na silagem (Pahlow et al., 2003), o que eleva as perdas de matéria seca e o valor nutritivo, repercutindo negativamente no desempenho produtivo dos animais.

Nesse contexto, diversos aditivos têm sido utilizados na ensilagem da cana-de-açúcar com a finalidade de interferir na dinâmica fermentativa, inibindo o desenvolvimento de 
microrganismos indesejáveis durante a fermentação do material ensilado. Estas medidas são tomadas com a finalidade de promover menores perdas de matéria seca, maior recuperação de carboidratos solúveis, inibindo a fermentação alcoólica e aumento na produção de ácido lático e/ou melhora da estabilidade aeróbia (Cavali et al., 2006; Santos et al., 2009). Entretanto, têm-se obtido resultados bastante variáveis (Freitas et al., 2006), destacando-se os alcalinizantes de meio, como os óxidos e carbonatos de cálcio.

O cloreto de sódio $(\mathrm{NaCl})$ é uma alternativa para contribuir e melhorar a qualidade das silagens, pois, dependendo da concentração em que é usado, torna-se antisséptico para a maioria dos microrganismos (Gava, 1984), por atuar na redução da atividade da água nos alimentos, limitar a solubilidade do oxigênio e modificar o pH. No entanto, o uso do cloreto de sódio na conservação de alimentos tem limitações, uma vez que reflete diretamente sobre a aceitabilidade dos alimentos (Araújo, 1990).

A vantagem da utilização do sal está na sua fácil aquisição pelos produtores rurais, por apresentar custo relativamente baixo. Levando-se em conta a situação atual da agropecuária, que visa reduzir custos e potencializar resultados, objetivou-se com este trabalho avaliar a inclusão de aditivos alcalinos sobre a estabilidade aeróbia de silagens de cana-de-açúcar.

\section{Material e Métodos}

O experimento foi conduzido no setor de Forragicultura da Faculdade de Zootecnia na Universidade José do Rosário Vellano (UNIFENAS), Campus de Alfenas, Minas Gerais. A cana-de-açúcar utilizada foi o cultivar SP81-3250 (grau brix $=19$ ), colhida manualmente aos 24 meses de crescimento e processada em picadeira estacionária, com intuito de obter partículas com tamanho médio entre 1,0 e 2,0 cm. Após a desintegração, a cana foi ensilada sem aplicação de aditivo ou com a aplicação de cloreto de sódio ( $\mathrm{NaCl}$ ), em níveis correspondentes a 0,5; 1,0 e 2,0\%, e cal virgem (CaO), 0,5; 1,0 e 1,5\% na matéria natural. De acordo com as análises realizadas no Laboratório de Análise de Alimentos da UNIFENAS, a cal virgem apresentava em sua composição teor mínimo de óxido de cálcio de 64,0; teor máximo de óxido de magnésio (MgO) de 1,5; e teor máximo de água de 1,0. Os aditivos foram aplicados antes do enchimento dos silos, a seco, e misturados à silagem de cana-de-açúcar em lonas plásticas buscando-se adequada uniformidade com a massa de forragem em cada nível de inclusão.
Utilizaram-se como silos experimentais tubos de PVC com capacidade para $4 \mathrm{~L}$. Cada tubo possuía uma tampa adaptada com válvula tipo Bunsen para o escape de gases e areia $(0,5 \mathrm{~kg})$ no fundo, separada da forragem por uma tela fina de plástico com malha adequada para evitar o contato entre a areia e a silagem, para quantificação de efluentes. A compactação foi realizada com auxílio de soquetes de madeira, com acomodação de camadas de aproximadamente $5 \mathrm{~cm}$ de espessura, obtendo-se uma massa específica entre 550 e $600 \mathrm{~kg}$ de matéria verde $/ \mathrm{m}^{3}$.

A perda total de MS (PMS) durante o período de ensilagem foi calculada pela diferença entre o peso da MS inicial e final nos silos, conforme descrito por Jobim et al. (2007) e Balieiro Neto et al. (2009).

$$
\mathrm{PMS}=\left[\frac{(\mathrm{MSi}-\mathrm{MSf})}{\mathrm{MSi}}\right] \times 100
$$

em que: $\mathrm{PMS}$ = perda total de MS (\%); $\mathrm{MSi}$ = quantidade de MS inicial, calculada pelo peso do silo após enchimento menos o peso do silo vazio (tampa, areia e tela) antes do enchimento (tara seca) multiplicado pelo teor de MS da forragem na ensilagem; MSf = quantidade de MS final, calculada pelo peso do silo cheio antes da abertura menos o peso do conjunto vazio, sem a forragem, após a abertura dos silos (tara úmida) multiplicado pelo teor de MS da forragem na abertura.

A perda por gases (PG) no processo de ensilagem foi obtida com base na pesagem dos silos no fechamento e na abertura, em relação à massa de forragem armazenada, descontando-se a tara do silo, conforme descrito por Jobim et al. (2007) e Balieiro Neto et al. (2009).

$\mathrm{PG}=[(\mathrm{PCen}-\mathrm{Pen}) * \mathrm{MSen}]-[(\mathrm{PCab}-\mathrm{Pen}) * \mathrm{MSab}] \times 100$

$$
[(\mathrm{PCen}-\mathrm{Pen}) * \mathrm{MSen}]
$$

em que: $\mathrm{PG}=$ perdas por gases ( $\%$ da MS); $\mathrm{PCen}=$ peso do silo cheio na ensilagem (kg); Pen = peso do conjunto (tubo, tampa, areia e tela) na ensilagem $(\mathrm{kg})$; MSen = teor de MS da forragem na ensilagem (\%); PCab = peso do silo cheio na abertura $(\mathrm{kg})$; MSab = teor de MS da forragem na abertura (\%).

A quantidade de efluentes (E) foi estimada pelo acréscimo no peso do conjunto tubo, areia e tela como descrita abaixo, conforme descrito por Jobim et al. (2007) e Balieiro Neto et al. (2009):

$$
\mathrm{E}=\frac{(\mathrm{Pab}-\mathrm{Pen})}{(\text { MVfe })} \times 1000
$$

em que: $\mathrm{E}$ = produção de efluente ( $\mathrm{kg} / \mathrm{t}$ de massa verde); $\mathrm{Pab}=$ peso do conjunto (tubo, areia e tela) na abertura (kg); Pen $=$ peso do conjunto (tubo, areia e tela) na ensilagem $(\mathrm{kg}) ; \mathrm{MVfe}=$ massa verde de forragem ensilada $(\mathrm{kg})$.

Após o descarte da camada superficial, parte da massa ensilada foi transferida para bandejas de plástico para 
posterior homogeneização. Após esse procedimento, amostras de 2,0 kg de silagem foram revolvidas para maior penetração de ar na massa e colocadas em baldes plásticos com capacidade para $6 \mathrm{~L}$ e transferidas para câmara climática a $19 \pm 1,5^{\circ} \mathrm{C}$, com umidade relativa média de $72 \%$. As temperaturas das silagens foram obtidas três vezes ao dia, com intervalo entre observações de 8 horas, durante quatro dias, com o uso de termômetro inserido a $10 \mathrm{~cm}$ no centro da massa de forragem conforme proposto por Kung Júnior et al. (2003) e Bernardes et al. (2007). No mesmo balde foram retiradas a cada coleta de temperatura, aproximadamente $15 \mathrm{~g}$ da massa para determinação dos valores de $\mathrm{pH}$, seguindo as metodologias descritas em Silva \& Queiroz (2002), caracterizando dessa forma um esquema de parcelas subdividas no tempo. A temperatura ambiente foi aferida com o uso de termômetro digital e o teor de MS determinado seguindo os procedimentos descritos por Campos et al. (2004).

Os parâmetros para avaliação da instabilidade aeróbia constituíram-se no aumento em $2^{\circ} \mathrm{C}$ da temperatura da silagem em relação ao ambiente após a abertura dos silos (Moran et al., 1996), número de horas para elevação da temperatura da silagem em $2^{\circ} \mathrm{C}$ em relação à temperatura ambiente, número de horas para atingir a temperatura máxima, temperatura máxima e soma das médias diárias de temperatura nas silagens expostas ao ar de 0 a 4 dias, conforme proposto por O’Kiely et al. (1999). Outro parâmetro utilizado para avaliação da estabilidade aeróbia das silagens foi o pH, pois segundo Cherney \& Cherney (2003), o pHé um bom indicador da qualidade de silagens com baixo teor de MS.

O delineamento experimental utilizado foi o totalmente ao acaso em esquema de parcela subdividida, em que os fatores avaliados nas parcelas foram os níveis de de cal virgem e cloreto de sódio e, nas subparcelas, os tempos em que as silagens ficaram em aerobiose, com quatro repetições. Os resultados obtidos foram analisados por meio do programa estatístico SISVAR ${ }^{\circledR}$ (Ferreira, 2000), em que as médias obtidas para cada nível de inclusão foram comparadas por Scott-knott e os valores encontrados no tempo de avaliação submetidos à análise de regressão a $5 \%$ de significância. Optou-se por modelar o comportamento de $\mathrm{pH}$ e temperatura somente em cinco tempos $(0,24,48,72$ e 96 horas) de avaliação, pelo fato de não encontrar modelos que fossem representativos nos treze tempos estudados.

\section{Resultados e Discussão}

Os teores de MS das massas ensiladas foram influenciados $(\mathrm{P}<0,01)$ pela inclusão dos aditivos. Os maiores valores foram observados nas silagens tratadas com óxido de cálcio, uma vez que esse aditivo tem alta porcentagem de MS (99,00\%) (Tabela 1). As silagens tratadas com cloreto de sódio apresentaram menores teores de MS, porém não diferiram estatisticamente da silagem controle, o que possivelmente está relacionado à ação higroscópica do sal, que faz com que as células da planta retenham mais água por possuírem um meio rico em soluto.

As perdas totais de MS (efluente + gases) foram influenciadas pelos níveis de cal virgem e cloreto de sódio $(\mathrm{P}<0,01)$ e variaram de 3,09 a 30,49\% nas silagens tratadas com $1,5 \%$ de cal e silagem sem aditivo (controle), respectivamente (Tabela 1). As silagens tratadas com cal, independentemente da dose, apresentaram menores perdas de MS. A perda por gás foi o que mais influenciou as perdas de MS na silagem tratada com $0,5 \%$ de cal, e as silagens tratadas com 1,0 e 1,5\% de cal apresentaram menores perdas de MS por gases (Tabela 1). As maiores perdas por gases foram observadas nas silagens tratadas com sal, que não diferiram estatisticamente da silagem controle, possivelmente em virtude da maior porcentagem de água retida nesse material, promovendo alterações no processo fermentativo. A silagem tratada com $0,5 \%$ de cal apresentou a maior $(\mathrm{P}<0,031)$ produção de efluentes, o que pode indicar alteração na integridade das células da planta alterando sua capacidade de retenção de água (Tabela 1). De acordo com Woolford (1978), citado por Balieiro Neto et al. (2009),

Tabela 1 - Porcentagem de matéria seca das massas antes da ensilagem e perdas fermentativas por efluentes e gases de silagens de canade-açúcar tratadas com óxido de cálcio e cloreto de sódio

\begin{tabular}{lccc}
\hline Item & Matéria seca (\%) & Perda de MS (\%) & Efluente (kg t/MV) \\
\hline Controle & $25,29 \mathrm{~B}$ & $30,49 \mathrm{~A}$ & $54,78 \mathrm{~B}$ \\
$0,5 \% \mathrm{CaO}$ & $32,18 \mathrm{~A}$ & $10,60 \mathrm{~B}$ & $70,16 \mathrm{~A}$ \\
$1,0 \% \mathrm{CaO}$ & $33,41 \mathrm{~A}$ & $5,45 \mathrm{~B}$ & $58,15 \mathrm{~B}$ \\
$1,5 \% \mathrm{CaO}$ & $33,14 \mathrm{~A}$ & $3,09 \mathrm{~B}$ & $41,43 \mathrm{~B}$ \\
$0,5 \% \mathrm{NaCl}$ & $27,21 \mathrm{~B}$ & $24,95 \mathrm{~A}$ & $0,55 \mathrm{C}$ \\
$1,0 \% \mathrm{NaCl}$ & $26,21 \mathrm{~B}$ & $28,06 \mathrm{~A}$ & $52,76 \mathrm{~B}$ \\
$2,0 \% \mathrm{NaCl}$ & $27,31 \mathrm{~B}$ & $25,07 \mathrm{~A}$ & $54,89 \mathrm{~B}$ \\
$\mathrm{CV}(\%)$ & 5,83 & 26,20 & $20,48 \mathrm{~A}$ \\
\hline
\end{tabular}


alguns aditivos podem alterar a integridade estrutural das células da planta e sua capacidade em reter água, levando à ruptura e ao vazamento de conteúdo celular. As atividades de respiração da planta e crescimento de microrganismos produzem água e contribuem para a formação de efluentes, embora neste trabalho não tenha sido observada maior produção de efluentes quando aplicadas doses maiores (1,0 e $2,0 \%$ de cal e sal), o que possivelmente pode ser explicado pela inibição no crescimento de microrganismos.

Os resultados encontrados nesta pesquisa para a perda de MS durante o processo de ensilagem até abertura dos silos experimentais foram semelhantes aos encontrados por Pedroso et al. (2005), que, em pesquisa com silagem de canade-açúcar acrescida de ureia, benzoato de sódio, sorbato de potássio, Lactobacillus plantarum e L. buchneri, observaram perda de MS em torno de 30\%. São superiores, no entanto, aos resultados obtidos por Balieiro Neto et al. (2009), que observaram variações de 19,0 a 23,0\%. Caetano et al. (2008) também observaram perdas que variaram de 14,23 a 21,48\% em silagens de cana-de-açúcar tratada ou não com aditivos alcalinizantes.

Os valores de $\mathrm{pH}$ apresentaram diferença $(\mathrm{P}<0,01)$ entre as silagens e o tempo em aerobiose. Os maiores valores foram encontrados para as silagens tratadas com óxido de cálcio (cal virgem) e o menor para a silagem controle (Tabela 2). Este resultado já era esperado, em decorrência da natureza fortemente alcalina do aditivo utilizado. Balieiro Neto et al. (2009) avaliaram a estabilidade aeróbia de silagens de canade-açúcar tratadas com cal virgem e observaram os maiores valores de pH para a silagem tratada com 2,0\% de cal (4,9 a 5,0).

As silagens tratadas com sal apresentaram $\mathrm{pH}$ inferior ao encontrado naquelas tratadas com cal, o que talvez possa ser explicado pela ação osmótica do sal, que, em virtude da redução da atividade de água do meio, resultou em menores valores de pH. Além disso, muitas bactérias láticas conseguem viver em determinadas concentrações de sal, produzindo

Tabela 2 - Valores de $\mathrm{pH}$ e temperatura $\left({ }^{\circ} \mathrm{C}\right)$ das silagens de cana-de-açúcar no momento da abertura dos silos e após quatro dias de exposição ao oxigênio

\begin{tabular}{lccccc}
\hline Item & \multicolumn{2}{c}{$\mathrm{pH}$} & & \multicolumn{2}{c}{ Temperatura $\left({ }^{\circ} \mathrm{C}\right)$} \\
\cline { 2 - 3 } \cline { 5 - 6 } & 10 dia & 40 dia & & 10 dia & 40 dia \\
\hline Controle & 3,02D & 3,10D & & $21,20 \mathrm{Aa}$ & $17,40 \mathrm{Bb}$ \\
$0,5 \% \mathrm{CaO}$ & $3,45 \mathrm{Bb}$ & $4,67 \mathrm{Aa}$ & & $19,35 \mathrm{Bb}$ & $23,00 \mathrm{Aa}$ \\
$1,0 \% \mathrm{CaO}$ & $3,74 \mathrm{~A}$ & $3,81 \mathrm{~B}$ & & $18,35 \mathrm{Ca}$ & $17,67 \mathrm{Bb}$ \\
$1,5 \% \mathrm{CaO}$ & $3,73 \mathrm{~A}$ & $3,81 \mathrm{~B}$ & & $18,65 \mathrm{Ca}$ & $17,10 \mathrm{Cb}$ \\
$0,5 \% \mathrm{NaCl}$ & $3,34 \mathrm{C}$ & $3,38 \mathrm{C}$ & & $18,55 \mathrm{Ca}$ & $17,12 \mathrm{Cb}$ \\
$1,0 \% \mathrm{NaCl}$ & $3,29 \mathrm{C}$ & $3,33 \mathrm{C}$ & & $18,62 \mathrm{Ca}$ & $16,97 \mathrm{Cb}$ \\
$2,0 \% \mathrm{NaCl}$ & $3,27 \mathrm{C}$ & $3,28 \mathrm{C}$ & & $18,67 \mathrm{Ca}$ & $17,25 \mathrm{Cb}$ \\
$\mathrm{CV}(\%)$ & \multicolumn{2}{c}{2,06} & & & \multicolumn{2}{c}{1,06} \\
\hline
\end{tabular}

Médias seguidas de mesma letra maiúscula dentro de colunas e mesma letra minúscula dentro de linhas não diferem entre si por Scott-knott (5\%). ácido lático (Gava, 1984) e sabidamente são as bactérias mais desejáveis durante o processo de fermentação (Siqueira et al., 2005). Por sua vez, o ácido lático possui valor de pKa de 3,7 a 3,8, contribuindo para o decréscimo do $\mathrm{pH}$.

Os baixos valores de $\mathrm{pH}$ encontrados nas silagens tratadas com sal possivelmente inibiram o crescimento de microrganismos proteolíticos e principalmente leveduras, que, segundo Oude Elferink et al. (2001), são os primeiros microrganismos a atuar na silagem no pós-abertura, sendo indesejáveis durante o processo de fermentação e após a abertura dos silos (Siqueira et al., 2005), implicando menor estabilidade aeróbia. Woolford (1975) avaliou o efeito do benzoato em diferentes valores de $\mathrm{pH}$ e observou que, conforme o pH diminuiu, a necessidade do aditivo na inibição de leveduras e fungos também reduzida, comprovando que valores baixos de $\mathrm{pH}$ inibem o desenvolvimento de microrganismos em geral.

Somente a silagem tratada com $0,5 \%$ de cal apresentou diferença $(\mathrm{P}<0,01)$ de $\mathrm{pH}$ do primeiro para o quarto dia (Tabela 2). Essa observação possivelmente se deve à volatilização de ácidos orgânicos, em virtude das altas temperaturas observadas para esta silagem, além do consumo de ácidos orgânicos por microrganismos deterioradores, favorecidos pelo melhor ambiente proporcionado por este tratamento.

Pela análise de regressão, notou-se interação entre o nível de inclusão dos aditivos e o tempo em que as silagens ficaram expostas ao oxigênio $(\mathrm{P}<0,01)$ sobre os valores de pH. Com o passar dos dias, observou-se elevação do pH nas silagens tratadas com cal virgem (Figura 1), principalmente na silagem tratada com $0,5 \%$ de cal. O aumento nos valores de pH tem mesma razão. Dessa forma, os microrganismos utilizam ácidos orgânicos como fonte de energia para crescimento, o que provoca deterioração aeróbia da silagem, conforme descrito por Pahlow et al. (2003). Bernardes et al. (2007) e Balieiro Neto et al. (2009) também encontraram acréscimo nos valores de $\mathrm{pH}$ em silagens de capim-marandu com o avanço do tempo de exposição ao oxigênio e silagem de cana-de-açúcar (aproximadamente 8,3 após 7 dias de avaliação), respectivamente, embora os valores observados nesta pesquisa estejam inferiores aos resultados obtidos por esses autores.

As silagens tratadas com sal, independentemente da dose utilizada, não sofreram alteração brusca de $\mathrm{pH}$ ao longo dos dias de avaliação, o que pode ser explicado pela ação osmótica exercida pelo sal (diminui a disponibilidade de água), replicando na maior dificuldade de reprodução dos microrganismos proteolíticos e leveduras (efeito antimicótico) (Figura 1). Mediante esse contexto, o sal 
representa um bom aditivo no aumento da estabilidade aeróbia para as silagens de cana-de-açúcar.

De acordo com as equações de regressão, foi obtido o pH máximo para cada silagem e o número de horas para atingi-lo. A silagem tratada com $0,5 \%$ de cal virgem foi a que apresentou o maior $\mathrm{pH}(4,39)$, e a silagem controle o menor valor $(3,15)$ (Tabela 2). Quando avaliado o número de horas gastas para se atingir o máximo $\mathrm{pH}$, observou-se que as silagens tratadas com $0,5 \%$ de cal virgem e $\mathrm{NaCl}$ alcançaram o valor máximo com 96 horas de exposição ao oxigênio, o que pode sugerir que são mais estáveis, no entanto, a silagem tratada com $0,5 \%$ de cal apresentou o maior $\mathrm{pH}$ entre todas as silagens, e também a maior variação, com alto valor de $\mathrm{pH}$ acumulado.

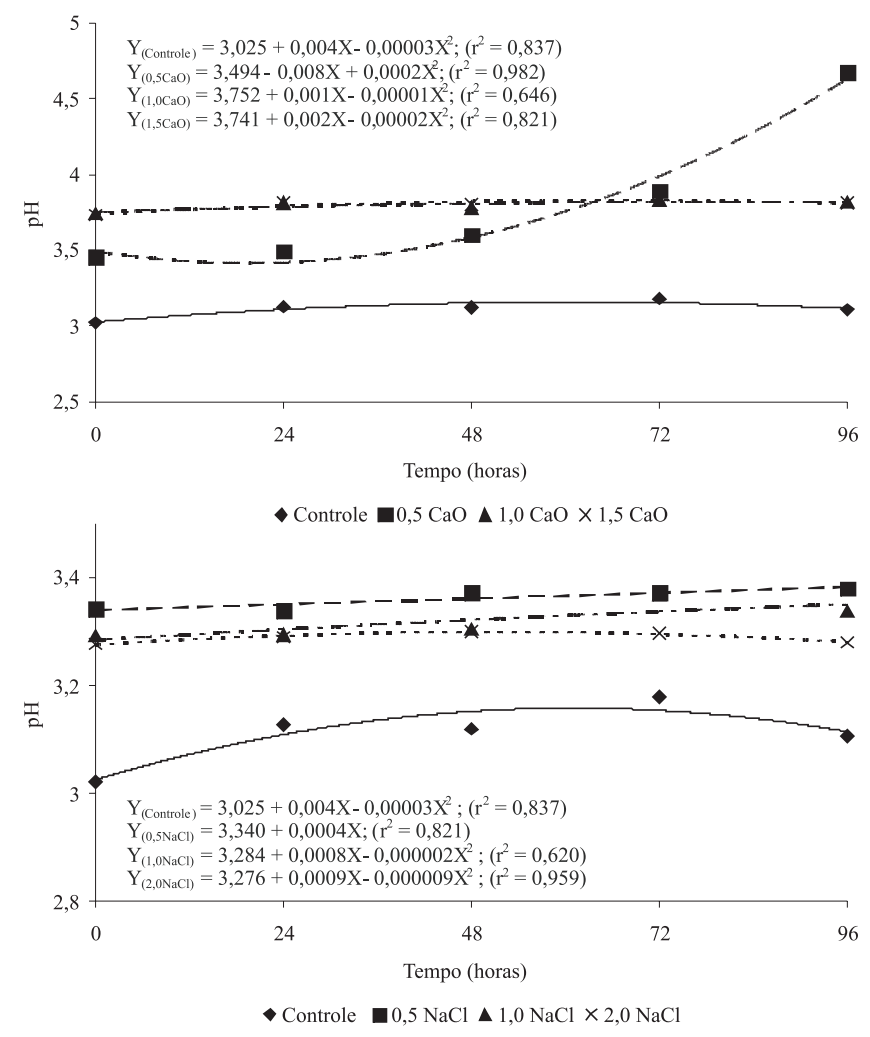

Figura 1 - pH da silagem controle e das silagens tratadas com óxido de cálcio (a) e cloreto de sódio (b).
Em análise conjunta dos dados de $\mathrm{pH}$, observou-se que a silagem tratada com $0,5 \%$ de cal foi a primeira a apresentar sinais de instabilidade aeróbia, e as demais silagens se mantiveram estáveis durante os dias de avaliação (Tabela 3; Figura 1).

As temperaturas das silagens foram influenciadas $(\mathrm{P}<0,01)$ pelos aditivos e pelo tempo em que ficaram expostas ao oxigênio: a maior temperatura no primeiro dia de exposição aeróbia (temperatura ambiente, $20,2{ }^{\circ} \mathrm{C}$ ) foi observada na silagem controle (Tabela 2). Já a maior temperatura no quarto dia de exposição aeróbia (temperatura ambiente, $17,5^{\circ} \mathrm{C}$ ) foi observada na silagem tratada com $0,5 \%$ de cal virgem, o que pode ser explicado pelo fato de este tratamento ter favorecido o processo fermentativo, tornando o ambiente propício ao desenvolvimento de microrganismos, principalmente fungos e leveduras (observação visual), que proporcionaram elevação da temperatura ocasionada pelos processos de respiração e assimilação das substâncias orgânicas realizadas por esses microrganismos. $\mathrm{O}$ aumento da temperatura da forragem em aerobiose, decorrente do crescimento de microrganismos aeróbicos (Woolford, 1978), envolve utilização de ácidos orgânicos e outros nutrientes solúveis como fonte de energia, resultando em perda de nutrientes.

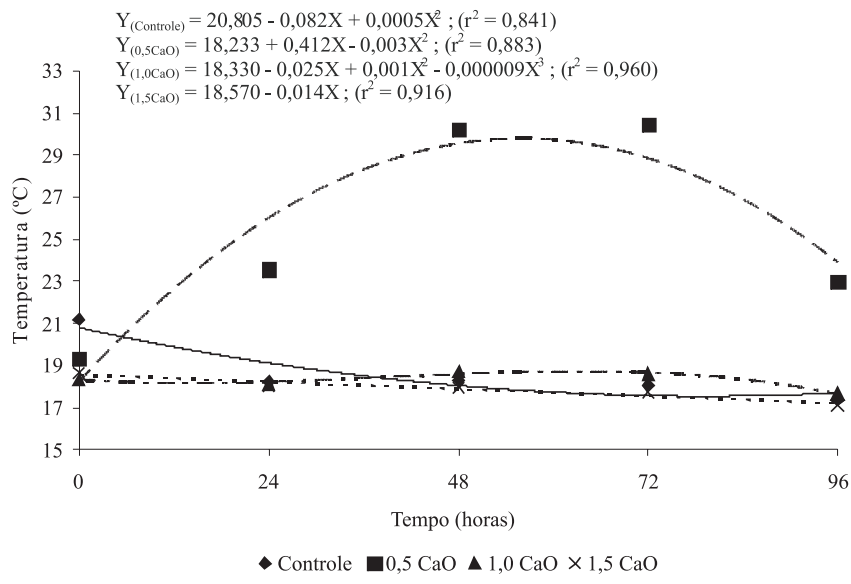

Figura 2 - Temperatura da silagem controle e das silagens tratadas com óxido de cálcio $(\mathrm{CaO})$.

Tabela 3 - pH máximo atingido pelas silagens, número de horas para a silagem atingir o máximo pH e pH acumulado das médias de todas as avaliações

\begin{tabular}{lcccc}
\hline Item & pH máximo & Horas para $\mathrm{pH}$ máximo & $\mathrm{pH}$ acumulado & CV (\%) \\
\hline Controle & 3,15 & 47 & 40,45 & 0,76 \\
$0,5 \% \mathrm{CaO}$ & 4,39 & 96 & 49,16 & 3,12 \\
$1,0 \% \mathrm{CaO}$ & 3,82 & 66 & 49,56 & 0,66 \\
$1,5 \% \mathrm{CaO}$ & 3,82 & 45 & 49,53 & 0,68 \\
$0,5 \% \mathrm{NaCl}$ & 3,38 & 96 & 43,82 & 0,87 \\
$1,0 \% \mathrm{NaCl}$ & 3,34 & 78 & 43,16 & 0,78 \\
$2,0 \% \mathrm{NaCl}$ & 3,28 & 19 & 42,82 & 0,99 \\
\hline
\end{tabular}


As doses de 1,0 e 1,5\% de cal foram efetivas em controlar o desenvolvimento dos microrganismos, refletindo em menores temperaturas (Figura 2), o mesmo observado para as silagens tratadas com cloreto de sódio (Figura 3). Esses resultados corroboram os obtidos por Balieiro Neto et al. (2009), que observaram os menores valores de temperatura para as silagens tratadas com 1,0 e 2,0\% de cal virgem.

De modo geral, no quarto dia de exposição aeróbia, as silagens tratadas com 0,5; 1,0 e 2,0\% de sal apresentaram temperaturas inferiores à daquelas tratadas com cal (exceto na dose de $1,5 \%)$, não apresentando diferença estatística (Tabela 2). Os menores valores observados para as silagens tratadas com sal refletem a ação antimicrobiana desse aditivo, devido a uma modificação no potencial osmótico da planta, inibindo o crescimento de microrganismos, entre eles, a levedura, que, após a abertura dos silos, são os primeiros a atuar nas silagens (Pahlow et al., 2003), ocasionando elevação da temperatura. De maneira geral, todas as doses de $\mathrm{NaCl}$ foram efetivas em diminuir a temperatura da silagem com o passar dos dias.

Segundo Gava (1984), o cloreto de sódio adicionado ao substrato alimentício limita a quantidade de água disponível, podendo inclusive desidratar o protoplasma da célula microbiana e promover a plasmólise, demonstrando a

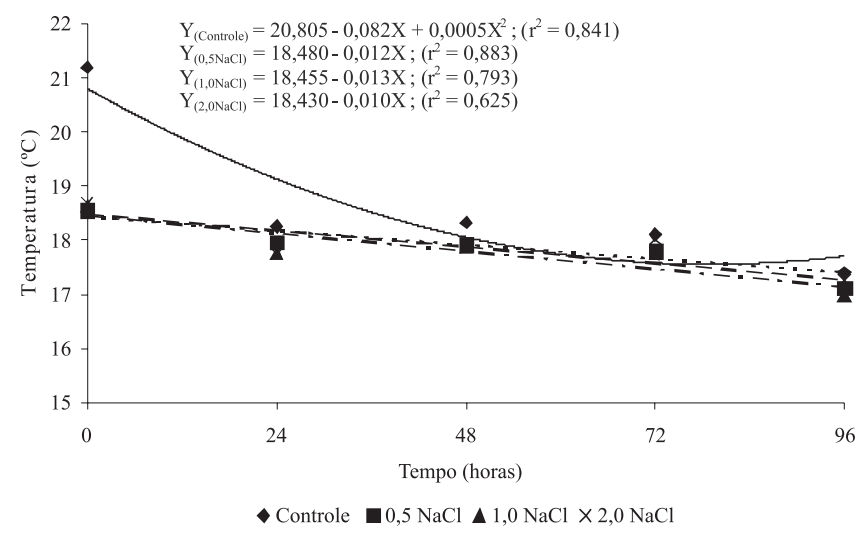

Figura 3 - Temperatura da silagem controle e das silagens tratadas com cloreto de sódio $(\mathrm{NaCl})$. viabilidade desse soluto como controlador do desenvolvimento de microrganismos após a abertura dos silos, implicando maior "tempo de cocho" das silagens.

Houve interação $(\mathrm{P}<0,01)$ entre o nível de inclusão dos aditivos e o tempo em que as silagens ficaram em aerobiose. Conforme descrito por Siqueira et al. (2005), quando se trata de avaliações na abertura dos silos, nem sempre se pode considerar que a primeira silagem a quebrar a estabilidade aeróbia (exemplo, $2^{\circ} \mathrm{C}$ acima da temperatura de referência) possa ser considerada a mais instável; devem ser considerados também a temperatura acumulada, a máxima temperatura observada, o tempo para alcançar a máxima temperatura e a taxa de elevação da temperatura, que é determinada por meio da variação dos ${ }^{\circ} \mathrm{C}$, em relação ao tempo necessário para alcançar a máxima temperatura (Tabela 4).

De acordo com os dados, podemos observar que a máxima temperatura foi atingida pela silagem tratada com $0,5 \%$ de cal, seguida da silagem que não recebeu aditivo (controle) (Tabela 4). Em relação ao número de horas gastas para se atingir a máxima temperatura, as silagens tratadas com 0,5 e 1,0\% de cal apresentaram temperatura máxima com 55 e 65 horas, respectivamente. No entanto, a silagem tratada com $0,5 \%$ de cal foi a primeira a atingir $2^{\circ} \mathrm{C}$ acima da temperatura ambiente, apresentando a maior variação entre as silagens. Com isso, foi também a primeira a apresentar sinais de deterioração aeróbia, enquanto as demais silagens se mantiveram estáveis.

Provavelmente a silagem tratada com $0,5 \%$ de cal apresentou maiores teores de carboidratos solúveis residuais, proporcionando meio propício ao maior desenvolvimento de microrganismos deterioradores. Silagens com problemas semelhantes, quando ofertadas aos animais, podem fazer com que os resultados zootécnicos sejam afetados indiretamente, e consequentemente ocasionar perdas econômicas aos produtores. Neste sentido, o uso de cloreto de sódio na silagem de cana-de-açúcar poderia ser uma boa alternativa no controle da deterioração aeróbia, além de ser facilmente adquirido nas propriedades rurais.

Tabela 4 - Variações de temperatura $\left({ }^{\circ} \mathrm{C}\right)$ das silagens de cana-de-açúcar tratadas com cal virgem e cloreto de sódio

\begin{tabular}{|c|c|c|c|c|c|}
\hline Item & $\begin{array}{l}\text { Temperatura } \\
\text { máxima }^{1}\end{array}$ & $\begin{array}{c}\text { Horas para máxima } \\
\text { temperatura }^{2}\end{array}$ & $\begin{array}{c}\text { Horas } \\
\text { aumentar } 2^{\circ} \mathrm{C}\end{array}$ & $\begin{array}{c}\text { Temperatura média } \\
\text { acumulada }\end{array}$ & CV (\%) \\
\hline Controle & 21,2 & 0 & $>96$ & 238,28 & 1,16 \\
\hline 0,5\% CaO & 33,75 & 56 & 16 & 337,88 & 7,00 \\
\hline $1,0 \% \mathrm{CaO}$ & 18,97 & 56 & $>96$ & 238,27 & 1,41 \\
\hline $1,5 \% \mathrm{CaO}$ & 18,65 & 0 & $>96$ & 230,29 & 0,79 \\
\hline $0,5 \% \mathrm{NaCl}$ & 18,55 & 0 & $>96$ & 230,61 & 0,81 \\
\hline $1,0 \% \mathrm{NaCl}$ & 18,62 & 0 & $>96$ & 229,34 & 0,62 \\
\hline $2,0 \% \mathrm{NaCl}$ & 18,67 & 0 & $>96$ & 230,82 & 1,10 \\
\hline
\end{tabular}




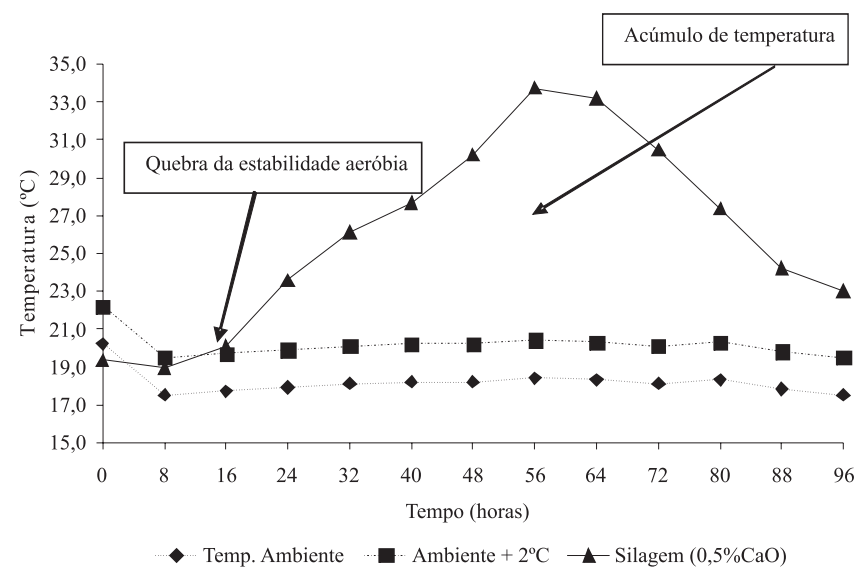

Figura 4 - Quebra da estabilidade aeróbia de silagens de cana-deaçúcar tratadas com óxido de cálcio a $0,5 \%$, em função da temperatura ambiente e acúmulo da temperatura ao longo do período avaliado (Adaptado de Siqueira et al., 2005).

A silagem tratada com $0,5 \%$ de cal virgem apresentou quebra da estabilidade aeróbia, decorrente da ação dos microrganismos deterioradores (Figura 4).

Os resultados encontrados nesta pesquisa para a temperatura máxima e o tempo gasto para atingir a temperatura máxima corroboram dados descritos por Caetano et al. (2008), que avaliaram a estabilidade aeróbia de silagens de cana-de-açúcar tratadas com aditivos químicos e observaram que o uso dos aditivos melhorou a estabilidade aeróbia, já que resultou em menor temperatura máxima e numa tendência de redução da taxa de elevação da temperatura, em que os melhores resultados foram encontrados para a silagem tratada com óxido de cálcio. Por sua vez, a dose de 1,0\% proporcionou menor temperatura máxima, enquanto os modos de aplicação não afetaram os parâmetros de estabilidade aeróbia.

\section{Conclusões}

O uso de cloreto de sódio como aditivo proporciona maior estabilidade aeróbia em silagens de cana-de-açúcar, evitando sua deterioração aeróbia, mesmo efeito observado com a utilização de cal virgem, exceto na dose de 0,5\%. Portanto, novas pesquisas são necessárias para avaliação do efeito desse aditivo sobre a estabilidade aeróbia de silagens de cana-de-açúcar e a aceitabilidade do alimento pelos animais.

\section{Referências}

ARAÚJO, J.M.A. Conservadores químicos em alimentos. Boletim da Sociedade Brasileira de Ciência e Tecnologia de Alimentos, v.24, n.3/4, p.192-210, 1990.
BALIEIRO NETO, G.; SIQUEIRA, G.R.; NOGUEIRA, J.R. et al. Perdas fermentativas e estabilidade aeróbia de silagens de canade-açúcar aditivadas com cal virgem. Revista Brasileira de Saúde e Produção Animal, v.10, n.1, p.24-33, 2009.

BERNARDES, T.F.; REIS, R.A.; SIQUEIRA, G.R. et al. Estabilidade aeróbia da ração total e de silagens de capim-marandu tratadas com aditivos químicos e bacterianos. Revista Brasileira de Zootecnia, v.36, n.4, p.754-762, 2007.

CAETANO, H.; SILVA, M.A.; MORENO, B.T. et al. Perfil fermentativo, perda de matéria seca e estabilidade aeróbia de silagens de cana-de-açúcar tratadas com aditivos químicos. In: REUNIÃO ANUAL DA SOCIEDADE BRASILEIRA DE ZOOTECNIA, 45., 2008, Lavras. Anais... Lavras: Sociedade Brasileira de Zootecnia, 2008. (CD-ROM).

CAMPOS, F.P.; NUSSIO, C.M.B.; NUSSIO, L.G. Métodos de análise de alimentos. Piracicaba: FEALQ, 2004. 135p.

CAVALI, J.; PEREIRA, O.G.; SOUSA, L.O. et al. Silagem de cana-deaçúcar tratada com óxido de cálcio: composição bromatológica e perdas. In: REUNIÃO ANUAL DA SOCIEDADE BRASILEIRA DE ZOOTECNIA, 43., 2006, João Pessoa. Anais... João Pessoa: Sociedade Brasileira de Zootecnia, 2006. (CD-ROM).

CHERNEY, J.H.; CHERNEY, D.J.R. Assessing silage quality. In: BUXTON, D.R.; MUCK, R.; HARRISON, J. (Eds.). Silage science and technology. Madison: American Society of Agronomy, 2003. p.141-198.

FERREIRA, D.F. Análises estatísticas por meio do SISVAR para windows, versão 4.0. In: REUNIÃO ANUAL DA SOCIEDADE INTERNACIONAL DE BIOMETRIA, São Carlos, 2000. Anais... São Carlos: Universidade Federal de São Carlos, 2000. p.225-258.

FREITAS, A.W.P.; PEREIRA, J.C.; ROCHA, F.C. et al. Características da silagem de cana-de-açúcar tratada com inoculante bacteriano e hidróxido de sódio e acrescida de resíduo da colheita de soja. Revista Brasileira de Zootecnia, v.35, n.1, p.48-59, 2006.

GAVA, A.J. Princípios de tecnologia de alimentos. São Paulo: Nobel, 1984. 284p.

JOBIM, C.C.; NUSSIO, L.G.; REIS, A.R. et al. Avanços metodológicos na avaliação da qualidade da forragem conservada. Revista Brasileira de Zootecnia, v.36, p.101-119, 2007 (supl.).

KUNG JUNIOR., L.; STOKES, M.R.; LIN, C.J. Silage additives. In: BUXTON, D.R.; MUCK, R.E.; HARRISON, J.H. (Eds.) Silage science and technology. Madison: American Society of Agronomy, 2003. p.305-360.

MORAN, J.P.; WEINBERG, G.; ASHBELL, Y.H. et al. A comparison of two methods for the evaluation of the aerobic stability of whole crop wheat silage. In: INTERNATIONAL SILAGE CONFERENCE, 11., 1996, Aberystwyth. Proceedings... Aberystwyth: University of Wales Aberystwyth, 1996. p.162-163.

O’KIELY, P.; MOLONEY, A.; KEATING, T. et al. Maximing output of beef within cost efficient, environmentally compatible forage conservation systems. Dunsany: Grange Research Centre, 1999. 64p. (Beef Productions Series, 10).

OUDE ELFERINK, S.J.W.H.; KROONEMAN, J.; GOTTSCHAL, J.C. et al. Anaerobic conversion of lactic acid to acetic acid and 1,2-propanediol by Lactobacillus buchneri. Applied and Environmental microbiology, v.67, p.125-132, 2001.

PAHLOW, G.; MUCK, R.E.; DRIEHUIS, F. et al. Microbiology of ensiling. In: BUXTON, D.R.; MUCK, R.E.; HARRISON, J.H. (Eds.) Silage science and technology. Madison: American Society of Agronomy, 2003. p.31-94.

PEDROSO, A.F.; NUSSIO, L.G.; PAZIANI, S.F. et al. Fermentation and epiphytic microflora dynamics in sugar cane silage. Scientia Agricola, v.62, n.5, p.427-432, 2005.

SANTOS, M.C.; NUSSIO, L.G.; MOURÃO, G.B. et al. Nutritive value of sugar cane silage treated with chemical additives. Scientia Agricola, v.66, p.159-163, 2009. 
SILVA, D.J.; QUEIROZ, A.C. Análise de alimentos: métodos químicos e biológicos. Viçosa, MG: UFV, 2002. 235p.

SIQUEIRA, G.R.; BERNARDES, T.F.; REIS, R.A. Instabilidade aeróbia de silagens: efeitos e possibilidades de prevenção. In: REIS, R.A.; SIQUEIRA, G.R.; BERTIPAGLIA, L.M.A. et al. (Eds.) Volumosos na produção de ruminantes. Jaboticabal: Funep, 2005. p.25-60.
WOOLFORD, M.K. Microbiological screening of food preservatives, cold sterilants and specific antimicrobial agents as potential silage additives. Journal of the Science of Food and Agricultural, v.26, p.229-237, 1975.

WOOLFORD, M.K. The problem of silage effluent. Herbage Abstracts, v.48, p.397-403, 1978 